\title{
Physical Activity and Healthy Eating Patterns in Public Schools in Brazil: A Strategy to Avert Risk Factors in Adulthood
}

\author{
Maria Cristina de Oliveira Izar ${ }^{\circledR}$ and Francisco Antonio Helfenstein Fonseca ${ }^{\circledR}$ \\ Escola Paulista de Medicina da Universidade Federal de São Paulo, São Paulo, SP - Brazil \\ Short Editorial related to the article: The Olympic Experimental Gymnasium Program and its Association with the Prevalence of Cardiovascular \\ Risk Factors in Adolescents: A Cross-Sectional Study
}

Cardiovascular disease (CVD) remains the leading cause of death globally, however, $80 \%$ of premature heart disease, stroke and diabetes can be prevented. ${ }^{1}$ Atherosclerotic cardiovascular disease (ASCVD) can begin in youth, exacerbated by exposure to factors associated with increased cardiovascular risk. ${ }^{2}$ There are interventions to prevent risk factors onset (primordial prevention), to identify and treat risk factors in childhood and adolescence (primary prevention) and to address the risk of additional events in those who already have ASCVD or other CVDs (secondary prevention) at a young age. ${ }^{3}$ Adolescence presents a prime opportunity to assess risk factors for CVD and to intervene to prevent its development.

The manuscript by Scherr et al. ${ }^{4}$ highlights the importance of a school-based program including physical activity (PA) and healthy eating patterns in adolescence for the prevention of cardiovascular risk factors.

The Olympic Experimental Gymnasium (OEG) is a project initiated by Rio de Janeiro's city government integrating academic and sports training. The schools participating in the OEG project provide sports practice (two hours a day, five times a week), and five healthy meals to students every day. In this article, the authors evaluate the influence of sports practice and healthy eating habits in OEG schools compared with PA once a week and one meal per day, in regular schools (RSch). The students had to be exposed to the interventions for one year prior to data collection. The authors aimed to examine potential associations between the school environment in OEG schools versus RSch and important CVD risk factors in adolescents. They hypothesized that the adolescents attending RSch would be more likely to have risk factors than those attending OEG schools.

In this cross-sectional study, a total of 1,113 students, from the same geographic region were included in a 2:1

\section{Keywords}

Adolescent; Exercise; Healthy Diet; Risk Factors/prevention and control.

Mailing Address: Maria Cristina Izar •

Universidade Federal de São Paulo Escola Paulista de Medicina - Rua Loefgren,

1350. Postal Code 04040-001, Vila Clementino, São Paulo, SP - Brazil

E-mail: mcoizar@cardiol.br, fahfonseca@terra.com.br

DOI: 10.5935/abc.20190099 allocation ratio to exposure (719 attending OEG schools) and non-exposure (394 attending RSch).

Although the study was cross-sectional, the students were included if they had participated in the OEG or RSch program for at least one year. Association between exposure and health status was addressed by a binomial logistic regression. The results of this program showed that the prevalence of prehypertension/hypertension and overweight differed among schools and that students attending OEG schools had lower proportion and odds of developing CVD risk factors. Higher body mass index, prehypertension/hypertension and overweight were more prevalent among RSch students. However, when analyzed by gender, girls had higher BMI and prevalence of overweight. After adjusting for sex and age, RSch students were more likely to have overweight (OR 1.49; 95\%Cl 1.13-1.98) or to be pre-hypertensive/ hypertensive (OR 1.86; 95\% Cl 1.36-2.34). No differences were found for total cholesterol, glycemia or triglycerides, according to school exposure.

As this study was cross-sectional, causality could not be inferred. Evaluation of exposure, but not the level of PA, baseline status of participants, and not only the effects of exposure are limitations of this study. Prospective studies, with cluster randomization of interventions, should be done to assess lifestyle modification in adolescence and the association with risk factors.

Recently, the American Heart Association issued a statement to guide cardiovascular risk reduction in high-risk pediatric patients. ${ }^{3}$ Although there are recommendations for high, moderate and at-risk categories, general strategies for lifestyle improvement are recommended for blood pressure, lipids (LDL-cholesterol and triglycerides), blood glucose, PA, diet, weight, and smoking in those who yet did not present these risk factors.

The major modifiable risk factors for CVD (smoking, hypertension, hypercholesterolemia, diabetes, and obesity) often begin in early life. ${ }^{5}$ Several studies have found that the number of CVD risk factors present in individuals correlates with the severity of atherosclerosis in both children and young adults. ${ }^{6-8}$ Initiatives to promote a better lifestyle must be encouraged in schools and adopted by policymakers, educators and stakeholders. In addition, in those at risk, an adequate risk stratification ${ }^{9}$ should be performed to avert the onset of cardiovascular risk factors. 


\section{Short Editorial}

\section{References}

1. Global Health Estimates 2016: Disease burden by Cause, Age, Sex, by Country and by Region, 2000-2016. Geneva, World Health Organization; 2018.

2. Expert Panel on Integrated Guidelines for Cardiovascular Health and Risk Reduction in Children and Adolescents, National Heart, Lung, and Blood In stitute. Expert Panel on Integrated Guidelines for Cardiovascular Health and Risk Reduction in Children and Adolescents: summary report. Pediatrics. 2011;128(suppl 5):S213-S56.

3. De Ferranti SD, Steinberger J, Ameduri R, Baker A, Gooding H, Kelly AS, et al. Cardiovascular Risk Reduction in High-Risk Pediatric Patients: A Scientific Statement From the American Heart Association. Circulation. 2019;139(13):e603-e634.

4. The Olympic Experimental Gymnasium Program and its association with the prevalence of cardiovascular risk factors in adolescents: a crosssectional study. Arq Bras Cardiol. 2019; 112(6):775-781.
5. Ford ES, Mokdad AH, Ajani UA. Trends in risk factors for cardiovascular disease among children and adolescents in the United States. Pediatrics 2004;114(6):1534-44

6. Berenson GS, Srinivasan SR, Bao W, Newman WP 3rd, Tracy RE, Wattigney WA. Association between multiple cardiovascular risk factors and atherosclerosis in children and young adults. The Bogalusa Heart Study. N Engl J Med 1998;338(23) 1650-6.

7. Raitakari OT, Juonala M, Kahonen M, Taittonen L, Laitinen T, Maki-Torkko $\mathrm{N}$, et al. Cardiovascular risk factors in childhood and carotid artery intimamedia thickness in adulthood: the Cardiovascular Risk in Young Finns Study. JAMA 2003;290(17):2277-83.

8. Dawson JD, Sonka M, Blecha MB, Lin W, Davis PH. Risk factors associated with aortic and carotid intima-media thickness in adolescents and young adults: the Muscatine Offspring Study. J Am Coll Cardiol 2009;53(24):2273-9.

9. Gooding HC, de Ferranti SD. Cardiovascular risk assessment and cholestero management in adolescents: getting to the heart of the matter. Curr Opin Pediatr. 2010;22(4):398-404. 